\title{
The Effectiveness of Tripod Position And Pursed Lips Breathing to Enhance Oxygen Saturation in Patients With COPD
}

\author{
Hilma Wahidati ${ }^{1}$, Sri Utami Dwiningsih ${ }^{1}$, Putrono ${ }^{1}$ \\ ${ }^{I}$ Nursing Department, Semarang Health Polytechnic \\ Corresponding author: iffahhanifah14@gmail.com
}

\begin{abstract}
Background: COPD is a pulmonary disease characterized by air obstruction in respiratory tract from bronchi to the bronchioles, which continuously occur progressively, and irreversible, and related with the inflammatory response due to toxic gases (cigarette smoke, factory pollution and vehicle pollution) so it can cause a desaturation oxygen (SpO2). This impact will caused in concentration decreased, functional activity reduction, hypoxemia, hypoxia until cyanosis. To prevent this impact, there are two non-pharmacological methods that can be applied, a tripod position and pursed lips breathing exercise.
\end{abstract}

Purpose: To determine the effectiveness of tripod position and pursed lips breathing to enhance oxygen saturation in patients with COPD.

Methods: The research used queasy experimental with pre-posttest design. This research used total sampling that have 34 samples COPD patient which is include in inclusion criteria in working area of Puskesmas Padangsari Semarang. The samples are divided into 2 treatment groups (tripod position groups and pursed lips breathing groups) that gives 15 minutes therapy 3 times within 3 continuous days. This research will begins from February until March 2019. Statistical test to determine the affectivity of each groups using non-parametric test (Mann-Whitney test).

Results: the result of this research shows differences effectiveness between tripod position and pursed lips breathing with $p$ value 0.00 with mean deviation before and after therapy of tripod position 0.29 and pursed lips breathing 1.23.

Conclusion: in this research shows that pursed lips breathing is most effective to enhance oxygen saturation in COPD patient compare with tripod position.

Keywords:

Tripod Position; Pursed Lips Breathing; COPD; Oxygen saturation

\section{LATAR BELAKANG}

Penyakit Paru Obstruktif Kronik (PPOK) menurut perkembangannya akan menjadi penyakit yang mematikan nomor tiga di dunia karena gejala awal yang tidak dirasakan oleh penderita. Di Indonesia pada tahun 2013 tercatat sebanyak 3,7 persen per mil penderita PPOK dengan frekuensi lebih tinggi pada laki-laki (WHO, 2015).

PPOK merupakan penyakit yang ditandai dengan hambatan aliran udara di saluran nafas (paru-paru) yang tidak sepenuhnya reversibel (WHO, 2015), yang terjadi terus-menerus 
yang bersifat progresif, serta berhubungan dengan respons inflamasi kronis pada saluran pernapasan dan paru-paru terhadap partikel atau gas yang beracun sehingga dapat menyebabkan penurunan saturasi oksigen pada tubuh (Global Initiative for Chronic Lung Disease, 2015).

Penurunan saturasi oksigen yang terjadi pada pasien PPOK terjadi pada saat serangan sesak nafas yang dialami. Sehingga jumlah oksigen dalam sel darah merah yang dibawa hemoglobin menuju jantung kiri dan dialirkan menuju kapiler perifer sedikit, gangguan suplai oksigen dalam darah pada arteri akan meyebabkan penurunan nilai saturasi oksigen yang akan berdampak buruk bagi tubuh penderita (Muttaqin, 2008).

Dampak yang sering terjadi pada pasien PPOK dengan nilai saturasi yang mengalami penurunan terus menerus akan mengakibatkan terjadinya hipoksemia dan berlanjut menjadi hipoksia yang akan mengakibatkan pada penurunan aktivitas fungsional seharihari, penurunan konsentrasi dan perubahan mood pada pasien PPOK. Keadaan sesak nafas yang dibiarkan terus menerus tanpa disadari akan menurunkan saturasi oksigen yang selanjutnya dapat menyebabkan sianosis pada penderita PPOK (Somantri, 2012).

Penanganan penurunan saturasi oksigen agar tidak menyebabkan hipoksemia, hipoksia dan sianosis dapat dilakukan dengan pemberian terapi non-farmakoligis yaitu pengaturan posisi dan latihan pernafasan. Pengaturan posisi yang dapat meringankan sesak nafas pada pasien PPOK adalah tripod position dan latihan pernafasan yang dapat mempengaruhi saturasi oksigen yaitu pursed lips breathing exercise (Somantri, 2012). Berdasarkan literatur yang meneliti tentang peningkatan saturasi oksigen pada pasien PPOK dengan pemberian metode baik dengan tripod position maupun pursed lips breathing, menunjukkan hasil bahwa dengan tripod position dan pursed lips breathing exercise dapat secara efektif meningkatkan saturasi oksigen pada pasien PPOK dengan serangan sesak nafas (Somantri, 2009).

Penelitian tentang tripod position yang telah dilakukan oleh Suyanti (2016), dan Bhatt et al (2009) menunjukkan bahwa tripod position dapat berpengaruh pada proses pernafasan serta dapat meningkatkan saturasi oksigen pada penderita PPOK. Penelitian yang dilakukan oleh Istiyani (2015) menyatakan bahwa dari 20 pasien PPOK, terdapat 19 pasien mengalami penurunan saturasi oksigen dan setelah diberikan intervensi tripod position terjadi peningkatan persentasi saturasi oksigen $(>95 \%)$. Serangkaian penelitian tentang pursed lips breathing yang telah dilakukan oleh Bianchi (2007), Ambrosino dan Serradori (2006), Ramos et al (2009), dan Kim et al (2012) menunjukkan bahwa pursed lips breathing dapat menigkatkan kondisi pernafasan pasien PPOK, yaitu meningkatkan saturasi oksigen. Penelitian yang dilakukan oleh Budiono (2017), menyatakan bahwa dari 24 pasien PPOK, sebesar 58\% mengalami penurunan saturasi oksigen di bawah normal $(<95 \%)$ dan setelah diberikan intervensi pursed lips breathing terjadi peningkatan saturasi oksigen dengan nilai normal ( $>95 \%)$.

Berdasarkan uraian diatas, karena adanya 2 terapi non-farmakologis yang dapat meningkatkan persentase saturasi oksigen dalam tubuh penderita PPOK, penelitian mengenai perbedaan efektivitas pemberian tripod position dan terapi pursed lips breathing exercise terhadap kenaikan saturasi oksigen pada pasien dengan PPOK. 


\section{TUJUAN}

Mengetahui perbedaan efektifitas pemberian tripod position dan terapi pursed lips breathing exercise terhadap peningkatan saturasi oksigen pada pasien dengan PPOK.

\section{METODE}

Penelitian ini menggunakan desain penelitian quasi eksperimental dengan rancangan pre test-post test design untuk mempelajari efektifitas pemberian tripod position dan pursed lips breathing exercise terhadap peningkatakn saturasi oksigen pada pasien PPOK. Dalam penelitian ini teknik memilih sampel yang digunakan adalah nonprobability sampling yaitu mengambil sampel yang sesuai dengan ketentuan atau persyaratan sampel dari populasi tertentu. Teknik pengambilan sampel yang dilakukan dalam penelitian ini adalah total sampling dengan jumlah sampel 34 responden.

Pada penelitian ini, analisis univariat data jenis numerik (jenis kelamin, usia, kebiasaan merokok, kontrol periksa puskesmas, sesak nafas yang dirasakan, lama menderita PPOK, konsumsi obat PPOK) penyajiannya menggunakan distribusi frekuensi mean, median, standar deviasi, minimal-maksimal dan.). Kemudian dilanjutkan dengan analisa bivariat yaitu menggunakan uji Wilcoxon dikarenakan data berdistribusi tidak normal.

\section{HASIL}

Pada penelitian ini didapatkan sampel sebanyak 34 responden yang sudah memenuhi kriteria inklusi, dimana responden ini dibagi menjadi 2 kelompok yaitu 17 responden sebagai kelompok 1 dengan perlakuan tripod position dan 17 responden sebagai kelompok 2 dengan perlakuan pursed lip breathing exercise.

Tabel 1 Distribusi responden $(n=34)$ berdasarkan usia dan jenis kelamin

\begin{tabular}{llcc}
\hline \multirow{2}{*}{ Karakteristik } & \multicolumn{2}{c}{ Jumlah Responden } \\
\cline { 2 - 3 } & Usia & Frekuensi (n) & Persentase (\%) \\
\hline & $45-55$ tahun & 11 & 14,7 \\
$56-65$ tahun & 17 & 32,4 \\
& $66-75$ tahun & 1 & 50,0 \\
& $76-85$ tahun & & 2,9 \\
& & & \\
& Jenis Kelamin & 23 & 62,6 \\
& Laki-laki & 11 & 37,4 \\
& Perempuan & & \\
\hline
\end{tabular}


Berdasarkan tabel 1 menunjukan karakteristik usia bahwa sebanyak 82,4\% penderita PPOK ada pada kategori usia 66- 75 tahun yaitu sebesar 17 responden $(50,0 \%)$, responden dengan usia 56-65 tahun sebanyak 11 responden $(32,4 \%)$, selanjutnya pada rentang usia 76-85 tahun jumlah responden hanya 1 responden $(2,9 \%)$. Karakteristik jenis kelamin bahwa sebanyak 23 sampel $(62,6 \%)$ penderita PPOK berjenis kelamin laki-laki.

Tabel 2 distribusi karakteristik kebiasaa merokok pada masing-masing kelompok

\begin{tabular}{lcccc}
\hline \multirow{2}{*}{ Kebiasaan Merokok } & \multicolumn{4}{c}{ Kelompok } \\
\cline { 2 - 5 } & \multicolumn{3}{c}{ Tripod Position } & Pursed Lips Breathing \\
\cline { 2 - 5 } & Frekuensi & Presentase & Frekuensi & Persentase \\
& $(\mathrm{n})$ & $(\%)$ & $(\mathrm{n})$ & $(\%)$ \\
\hline Aktif & 11 & 50 & 11 & 50 \\
Pasif & 6 & 50 & 6 & 50 \\
\hline
\end{tabular}

Berdasarkan hasil distribusi karakteristik kebiasaan merokok pada masing-masing kelompok, sebanyak masing masing 11 (50\%) orang perokok aktif berdistribusi pada kelompok tripod osition dan pursed lips breathing.

Tabel 3 Distribusi responden $(n=34)$ berdasarkan kebiasaan kontrol ke puskesmas

\begin{tabular}{lcc}
\hline Kontrol Periksa Puskesmas & \multicolumn{2}{c}{ Jumlah Responden } \\
\cline { 2 - 3 } & Frekuensi (n) & Persentase (\%) \\
\hline & & \\
Saat kambuh & 16 & 47,1 \\
Saat keadaan semakin memburuk & 12 & 35,3 \\
Rutin periksa & 6 & 17,6 \\
\hline
\end{tabular}

Pada tabel 3 menunjukan karakteristik kebiasaan kontrol ke puskesmas bahwa sebanyak $28(82,4 \%)$ sampel hanya periksa ke puskesmas jika sakit yang dirasakan kambuh dan kondisi tubuh yang semakin memburuk.

Tabel 4 Distribusi responden $(n=34)$ berdasarkan sesak napas yang dirasakan

Sesak Napas Yang Dirasakan Jumlah Responden Frekuensi (n) $\quad$ Persentase (\%)

Tidak ada sesak kecuali dengan aktivitas 17 50,0

berat

Sesak jika berjalan cepat atau naik 1 lantai

Berjalan lebih lambat karena sesak

926,5

Sesak timbul jika berjalan 100 meter

$7 \quad 20,6$

12,9


Hasil dari tabel 4 menunjukan karakteristik sesak napas yang dirasakan bahwa sebanyak $17(50,0 \%)$ sampel tidak mengalami sesak napas kecuali saat aktivitas berat sedangkan hanya $1(2,9 \%)$ sampel yang mengalami sesak napas saat berjalan 100 meter.

Tabel 5 Distribusi responden $(\mathrm{n}=34)$ berdasarkan lama menderita PPOK

\begin{tabular}{lcc}
\hline Lama Menderita PPOK & \multicolumn{2}{c}{ Jumlah Responden } \\
\cline { 2 - 3 } & Frekuensi (n) & Persentase (\%) \\
\hline 1-3 bulan & 5 & 14,7 \\
4 - 6 bulan & 5 & 14,7 \\
7 - 12 bulan & 11 & 32,4 \\
$>1$ tahun & 13 & 38,2 \\
\hline
\end{tabular}

Berdasarkan tabel 5 menunjukan karakteristik lama menderita PPOK bahwa sebanyak $24(70,8 \%)$ sampel sudah menderita PPOK lebih dari 7 bulan lamanya.

Tabel 6 Distribusi saturasi oksigen sebelum diberikan perlakuan tripod position dan pursed lips breathing

\begin{tabular}{|c|c|c|c|c|}
\hline Variabel & Mean & SD & Min-Max & CI \\
\hline $\begin{array}{l}\text { Saturasi Oksigen } \\
\text { Sebelum tripod position }\end{array}$ & 94,47 & 0,71 & $93-95$ & $94,10-94,83$ \\
\hline $\begin{array}{l}\text { Saturasi Oksigen Sebelum } \\
\text { pursed lips breathing }\end{array}$ & 94,0 & 1,0 & $92-95$ & $93,48-94,51$ \\
\hline
\end{tabular}

Tabel 6 menunjukkan karakteristik responden berdasarkan saturasi oksigen sebelum diberikan perlakuan tripod position dan saturasi oksigen sebelum diberikan perlakuan pursed lips breathing. Rata-rata saturasi oksigen responden pada kelompok 1 sebelum dilakukan intervensi tripod position menunjukkan sebesar 94,47\% sedangkan pada kelompok 2 sebelum dilakukan intervensi pursed lips breathing menunjukkan sebesar 94,0\%. Saturasi oksigen perifer terendah pada kelompok 1 dengan intervensi tripod position sebesar 93\% sedangkan pada kelompok 2 dengan intervensi pursed lips breathing sebesar 92\%. Nilai saturasi oksigen perifer tertinggi pada kelompok 1 intervensi tripod position sebesar 95\% dan pada kelompok 2 intervensi pursed lips breathing sebesar $95 \%$. 
Tabel 7 hasil uji wilcoxon tindakan tripod position. Perbedaan saturasi oksigen sebelum dan sesudah dilakukan tripod position

\begin{tabular}{cccccc}
\hline Kelompok & Intervensi & Mean & $\Delta$ mean & SD & Nilai $\mathrm{p}$ \\
& & & & & \\
\hline Tripod Position & Pre test & 94,47 & 0,29 & 0,71 & 0,25 \\
& Post test & 94,76 & & 0,75 & \\
\hline
\end{tabular}

Berdasarkan tabel 7 menunjukkan selisih rata-rata saturasi oksigen pada kelompok 1 dengan perlakuan tripod position adalah 0,29 . Hasil uji wilcoxon menunjukkan p-value pada kelompok kontrol sebesar 0,25 ( $\mathrm{p}>0,05)$ yang secara statistik meiliki arti tidak ada perbedaan saturasi oskigen yang bermakna antara sebelum dan setelah dilakukan tripod position pada kelompok perlakuan 1 .

Tabel 8 hasil uji paired sample T test tindakan pursed lips breathing. Perbedaan saturasi oksigen sebelum dan setelah dilakukan Pursed Lip Breathing Exercise

\begin{tabular}{lccccc}
\hline Kelompok & Variabel & Mean & $\Delta$ mean & SD & Nilai p \\
& & & & & \\
\hline Pursed lips breathing & Pre test & 94,00 & 1,23 & 1,00 & 0,000 \\
& Post test & 95,23 & & 1,03 & \\
\hline
\end{tabular}

Hasil tabel 8 menunjukkan selisih rata-rata saturasi oksigen perifer pada pre test dan post test kelompok 2 dengan perlakuan pursed lips breathing adalah 1,23. Hasil uji paired sample T test menunjukkan p-value pada kelompok kontrol sebesar 0,000 ( $\mathrm{p}<$ $0,05)$ yang menunjukkan ada perbedaan yang bermakna pada hasil pre test dan post test saturasi oksigen kelompok 2 dengan perlakuan pursed lips breathing.

Tabel 9 perbedaan selisih nilai saturasi oksigen $\left(\mathrm{SpO}_{2}\right)$ sebelum dan sesudah dilakukan tindakan tripod position dan pursed lips breathing

\begin{tabular}{|c|c|c|c|}
\hline \multirow[t]{2}{*}{ Variabel saturasi oksigen $\left(\mathrm{SpO}_{2}\right)$} & \multicolumn{2}{|c|}{ Kelompok } & \multirow{2}{*}{$\begin{array}{c}p \\
\text { value }\end{array}$} \\
\hline & Tripod position & $\begin{array}{c}\text { Pursed lips } \\
\text { breathing }\end{array}$ & \\
\hline \multicolumn{4}{|l|}{ Sebelum } \\
\hline Mean $\pm S D$ & $94.47 \pm 0.71$ & $94.00 \pm 1.00$ & \\
\hline \multicolumn{4}{|l|}{ Setelah } \\
\hline Mean $\pm S D$ & $94.76 \pm 0.75$ & $95,23 \pm 1.03$ & \\
\hline \multicolumn{4}{|l|}{ Rerata selisih } \\
\hline Mean & 0.29 & 1.23 & 0.00 \\
\hline
\end{tabular}

Tabel 9 menunjukkan hasil bahwa ada perbedaan hasil selisih rerata pada sebelum tindakan dan setelah tindakan pada kedua kelompok sampel. Rata-rata selisish 
peningkatan saturasi oksigen $\left(\mathrm{SpO}_{2}\right)$ pada kelompok 1 dengan tripod position adalah 0.29 , sedangkan rata-rata selisih peningkatan pada kelompok 2 dengan pursed lips breathing adalah 1.23. Hasil $p$ value pada uji analisis menggunakan uji Mann-Whitney dapat disimpulkan bahwa ada perbedaan yang bermakna pada rata-rata selisish peningkatan saturasi oksigen $\left(\mathrm{SpO}_{2}\right)$ antara kelompok tripod position dan pursed lips breathing diperoleh sig. $(2$-tailed) $0.00(<0.05)$.

\section{PEMBAHASAN}

Saturasi oksigen pada penderita PPOK sebelum dilakukan tindakan menunjukkan nilai saturasi oksigen kurang dari nilai normal yaitu $\leq 95 \%$ hingga 92\%. Saturasi oksigen bagi penderita PPOK akan mengalami penurunan hingga $<85 \%$, hal ini terjadi karena adanya sumbatan jalan napas, penurunan fungsi otot diafragma dan udara yang terjebak dalam paru, sehingga pertukaran udara dalam paru tidak terjadi (Wikim, 2007).

Hasil penelitian ini menunjukkan bahwa berdasarkan karakteristik usia pada responden sebesar $82,4 \%$ penderita PPOK dengan penurunan saturasi oksigen berada pada usia 5675 tahun. Resiko untuk terkena PPOK meningkat seiring dengan bertambahnya usia. Sistem kardivaskuler dan respirasi akan mengalami penurunan daya tahan dan fungsinya pada usia > 50 tahun (Fajrin dan Baharudi, 2015).

Berdasarkan kebiasaan merokok menunjukkan sebesar 22 orang $(64,7 \%)$ penderita PPOK memiliki riwayat merokok. Penelitian yang dilakukan Firdausi (2014) menunjukkan sebanyak $84,3 \%$ responden PPOK memiliki riwayat perokok. Rokok adalah penyebab utama timbulnya PPOK, dengan resiko 30 kali lebih besar pada perokok beresiko menderita PPOK dibandingkan dengan yang bukan perokok dan merupakan penyebab dari 85-90\% kasus PPOK (WHO Commite on Smoking Control, 2015).

Hasil penelitian yang menunjukkan berdasarkan karakteristik kepatuhan kontrol periksa di Puskesmas yaitu sebanyak 28 responden $(82,4 \%)$ pergi berobat ke puskesmas saat sedang kambuh dan kondisinya semakin memburuk. Hasil yang sama dinyatakan oleh penelitian Anita Mursiany (2013) bahwa semakin tinggi rutinitas kontrol periksa, maka hasil terapi akan semakin membaik dan menurunkan komplikasi pada penderita PPOK. Karakteristik responden berdasarkan derajat sesak napas memiliki hasil bahwa 17 responden $(50,0 \%)$ mengalami sesak napas derajat 1 yaitu hanya sesak nafas saat beraktivitas berat. Hasil penelitian yang sama dilakukan oleh Mahler DA (2012) menunjukkan bahwa penderita PPOK paling banyak menderita sesak napas pada derajat 1 yaitu sebesar $37,6 \%$. Semakin tinggi derajat sesak napas, semakin tinggi pula derajat PPOK.

Hasil penelitian menunjukkan bahwa rata - rata nilai saturasi oksigen pada pasien PPOK sebelum dilakukan tripod position adalah 94,47 dengan standar deviasi 0,71 dan setelah dilakukan intervensi tripod position selama 3 hari berturut - turut salam 15 menit, rata - rata nilai saturasi oksigen adalah 94,76 dengan standar deviasi 0,75. Hasil uji wilcoxon menunjukkan bahwa tidak ada pengaruh yang signifikan pada pemberian tripod position terhadap peningkatan nilai saturasi oksigen dengan nilai $p 0,25(>0,05)$. Dapat diartikan bahwa pemberian tripod positon tidak memberikan pengaruh yang bermakna terhadap peningkatan nilai saturasi oksigen $\left(\mathrm{SpO}_{2}\right)$. Hasil penelitian ini sesuai 
dengan penelitian yang dilakukan oleh Ki-Song Kim (2012) yang menunjukkan bahwa hasil pemberian tripod position lebih efektif dalam meningkatkan aktivitas otot pernapasan dibandingkan dengan pengaruhnya terhadap peningkatan saturasi oksigen. Kera dan Maruyama (2008) menuliskan hasil penelitian yang sama yaitu pada pemberian terapi condong ke depan dengan siku sebagai tumpuan pada lutut (tripod position) tidak memberikan perbedaan yang signifikan antara saturasi oksigen dan tidal volume.

Berdasarkan hasil penelitian ini menunjukkan bahwa rata - rata nilai saturasi oksigen pada pasien PPOK sebelum dilakukan pursed lips breathing dengan full fowler adalah 94,00 dengan standar deviasi 1,00 dan setelah dilakukan intervensi pursed lips breathing selama 3 hari berturut - turut salam 15 menit, rata - rata nilai saturasi oksigen adalah 95,23 dengan standar deviasi 1,03. Hasil uji paired sample t test menunjukkan bahwa ada pengaruh yang signifikan pada pemberian pursed lips breathing terhadap peningkatan nilai saturasi oksigen dengan nilai $p 0,00(<0,05)$. Hasil penelitian ini sesuai dengan penelitian Budiono et al (2017) bahwa ada pengaruh yang signifikan tehadap peningkatan saturasi oksigen $\left(\mathrm{SpO}_{2}\right)$ sebelum dan setelah dilakukan pursed lips breathing dengan $p$ value $0.00(<0.05)$. Khasanah S (2017) juga menyatakan hasil penelitian yang sama bahwa pursed lips breathing secara efektif menurunkan frekuensi pernapasan dan meningkatkan saturasi oksigen $\left(\mathrm{SpO}_{2}\right)$.

Hasil analisa uji keefektifitasan menggunakan Mann-Whitney diperoleh $p$ value sig. (2tailed) $0,00(<0,05)$ yang menunjukkan Ha diterima dan ada perbedaan efektifitas penggunaan tripod postion dan pursed lips breathing exercise terhadap peningkatan saturasi oksigen pada pasien PPOK. Rerata selisih peningkatan saturasi oksigen pada kelompok dengan tripod position adalah 0,29 sedangkan rerata selisih peningkatan pada kelompok pursed lips breathing adalah 1,23. Berdasarkan hasil selisih rerata, pursed lips breathing lebih efektif terhadap peningkatan saturasi oksigen $\left(\mathrm{SpO}_{2}\right)$ pada penderita PPOK debandingkan dengan tripod position. Hasil penelitian ini sesuai dengan Budiono (2017) bahwa ada perbedaaan statistik yang signifikan pada saturasi oksigen sebelum dan setelah dilakukan pursed lips breathing pada penderita PPOK dan dapat disimpulkan bahwa pursed lips breathing efektif untuk meningkatkan saturasi oksigen dengan $p$ value $0.00(<0,05)$. Berdasarkan teori Faager $(2008)$ bahwa melalui kuat dan dalamnya mekanisme inspirasi, pursed lips breathing membantu meningkatkan masuknya oksigen ke alveoli.

\section{SIMPULAN}

Hasil analisis dengan menggunakan uji Mann-Whitney test menunjukkan ada perbedaan efektifitas yang signifikan terhadap kelompok tripod position dan pursed lips breathing terhadap peningkatan saturasi oksigen yang menunjukkan bahwa pursed lips breathing lebih efektif dibandingkan dengan tripod position.

\section{REFERENSI}

Ambrosino, N \& Serradori, N. (2006). Comprehensive Treatment of Dyspnoea in Chronic Obstructive Pulmonary Disease Patients. University Hospital of Pisa: Long Termhealth Care. 
Bhatt, Guleria, Luqman, Gupta, Mohan, A., Nanda, S. \& Stoltzfus, J.C. (2009). Effect Of Tripod Position On Objective Parameters Of Respiratory Function In Stable Chronoc Obstructive Pulmonary Disease. Indian J Chest Dis Allied Sci. 51:83-85

Bianchi, R. (2007). Pattern of chest wall kinematics during volitional pursed-lips breathing in COPD at rest. Elsevier Respiratory medicine. diakses 15 November 2018. doi:10.1016/j.rmed.2007.01.021

Budiono. (2017). The Effect Of Pursed Lips Breathing In Increasing Oxygen Saturation In Patients With Chronic Obstructive Pulmonary Disease In Internal Ward 2 Of The General Hospital Of DR. R. Soedarsono Pasuruan. Diakses tanggal 20 Oktober 2018. http://stikbar.org/vcabpublisher/index.php/PHI/index

Fajrin, O \& Baharuddin, L. (2015). Gambaran Status Pernapasan Dan Fungsi Paru Pada Penderita PPOK Di Poli Paru RSUD Arifin Achmad. Hom FK Volume 2 No.2. Diakses pada tanggal 28 Desember 2018.

Global Initiative for Chronic Obstructive Pulmonary Disease (GOLD). (2015).Global Strategy for The Diagnosis, Management and Prevention of Chronic Obstructive Pulmonary Disease. USA:MCR VISION,Inc.

Ki-Song, K., Min-Kwang, B., Won-Hwee, L., Heon-Seok, C., Oh-Yun, K \& ChungHwi Y. (2012). Effects Of Breathing Menuever And Sitting Posture On Muscle Activity In Inspiratoryaccessory Muscle In Patients With Chronic Obstructive Pulmonary Disease, Multidisciplinary Respiratory Medicine. diakses 25 Oktober 2018 dari http:/www.mrmjournal.com/content/7/1/9

Kim. (2012). Effects Of Balloon-Blowing Exercise On Lung Function Of Young Adult Smokers. J. Phys.

Mahler, D.A., Gifford, A.H., Wateman, L.A., Ward, J., Machala, S \& Baird, J.C. (2012). Mechanism Od Greater Oxygen Desaturation During Walking Compared With Cycling In COPD. Chest Jornal. DOI 10.1378/chest.10-2415. Diakses tanggal 28 September 2018.

Mursiany, A . (2013). Gambaran Penggunaan Obat Dan Kepatuhan Mengkonsumsi Obat Pada Penyakit PPOK Di Instalasi Rawat Jalan RSUD Kraton Pekalongan. Program Studi Farmasi Universitas Pekalongan.

Muttaqin, A. (2008). Asuhan keperawatan Klien dengan Gangguan Sistem Pernapasan. Jakarta: Salemba medika.

Ramos. (2009). Influence of pursed-lips breathing on heart rate variability and cardiorespiratory parameters in subjects with chronic obstructive pulmonary disease (COPD). Rev Bras fisioter, Sao Carlos. V.13,n. 4, p. 288-93 